Review Article

\title{
Beer Polyphenols and Menopause: Effects and Mechanisms-A Review of Current Knowledge
}

\author{
Berner Andrée Sandoval-Ramírez, ${ }^{1}$ Rosa M. Lamuela-Raventós, ${ }^{1,2}$ Ramon Estruch, ${ }^{2,3}$ \\ Gemma Sasot, ${ }^{1,2}$ Monica Doménech, ${ }^{2,3}$ and Anna Tresserra-Rimbau ${ }^{1,2}$ \\ ${ }^{1}$ Department of Nutrition, Food Science and Gastronomy, XaRTA, INSA, School of Pharmacy and Food Sciences, University of \\ Barcelona, Barcelona, Spain \\ ${ }^{2}$ CIBER Fisiopatología de la Obesidad y Nutrición (CIBEROBN), Instituto de Salud Carlos III, Madrid, Spain \\ ${ }^{3}$ Hospital Clinic, Institut d'Investigacions Biomèdiques August Pi i Sunyer, University of Barcelona, Barcelona, Spain
}

Correspondence should be addressed to Anna Tresserra-Rimbau; annatresserra@ub.edu

Received 4 April 2017; Revised 26 June 2017; Accepted 10 July 2017; Published 17 August 2017

Academic Editor: Giuseppe Cirillo

Copyright (C) 2017 Berner Andrée Sandoval-Ramírez et al. This is an open access article distributed under the Creative Commons Attribution License, which permits unrestricted use, distribution, and reproduction in any medium, provided the original work is properly cited.

\begin{abstract}
Beer is one of the most frequently consumed fermented beverages in the world, and it has been part of the human diet for thousands of years. Scientific evidence obtained from the development of new techniques of food analysis over the last two decades suggests that polyphenol intake derived from moderate beer consumption may play a positive role in different health outcomes including osteoporosis and cardiovascular risk and the relief of vasomotor symptoms, which are commonly experienced during menopause and are an important reason why women seek medical care during this period; here, we review the current knowledge regarding moderate beer consumption and its possible effects on menopausal symptoms. The effect of polyphenol intake on vasomotor symptoms in menopause may be driven by the direct interaction of the phenolic compounds present in beer, such as 8-prenylnaringenin, 6-prenylnaringenin, and isoxanthohumol, with intracellular estrogen receptors that leads to the modulation of gene expression, increase in sex hormone plasma concentrations, and thus modulation of physiological hormone imbalance in menopausal women. Since traditional hormone replacement therapies increase health risks, alternative, safer treatment options are needed to alleviate menopausal symptoms in women. The present work aims to review the current data on this subject.
\end{abstract}

\section{Introduction}

Beer is one of the most frequently consumed alcoholic beverages in the world. Beer consumption ranks first in Europe, slightly above wine consumption, according to the World Health Organization [1] and third amongst alcoholic beverage preferences in North America [2]. Archaeological findings show that Chinese villagers brewed fermented alcoholic drinks as far back as $7000 \mathrm{BC}$ on a small individual scale, with a production process and methods similar to those of ancient Egypt and Mesopotamia [3]. Throughout human history, products, ingredients, procedures, and techniques have evolved due to technological advances and the implementation of industrialized processes [4] further enhancing the long history of beer as a part of the human diet.
During the last two decades, scientific evidence has suggested that moderate consumption of alcoholic beverages has positive outcomes on different aspects of cardiovascular risk, as evidenced by Nogueira et al. who correlated regular daily intake of $330 \mathrm{ml}$ of beer with positive changes in insulin sensitivity and lipid profiles [5]. Fermented beverages have also shown positive associations with different cardiovascular disease endpoints such as coronary heart disease, peripheral arterial disease, chronic heart failure, and stroke in which regular moderate consumption of alcohol reduced the prevalence of adverse events [6], and fermented beverages have shown anti-inflammatory properties [7]; these findings may explain the benefits of regular and moderate alcohol intake on cardiovascular disease risk [8-11]. In the last decade, the development of new techniques for food analysis has allowed 
TABLE 1: Flavonoids contained in different types of beer.

\begin{tabular}{|c|c|c|c|c|}
\hline \multirow{2}{*}{ Molecule } & \multicolumn{4}{|c|}{ Mean content $(\mathrm{mg} / 100 \mathrm{ml})$} \\
\hline & Alcohol-free & Ale & Dark & Regular \\
\hline \multicolumn{5}{|l|}{ Chalcones } \\
\hline Xanthohumol & 0.0003 & 0.0100 & 0.0300 & 0.0014 \\
\hline \multicolumn{5}{|l|}{ Flavanols } \\
\hline Catechin & 0.1000 & 0.3300 & 0.0200 & 0.1100 \\
\hline Epicatechin & 0.0056 & 0.0500 & 0.0100 & 0.0600 \\
\hline Procyanidin dimer B3 & & & & 0.1600 \\
\hline Procyanidin trimer $\mathrm{C} 2$ & & & & 0.0300 \\
\hline Prodelphinidin trimer $\mathrm{C}-\mathrm{GC}-\mathrm{C}$ & & & & 0.0200 \\
\hline Prodelphinidin trimer GC-C-C & & & & 0.0100 \\
\hline Prodelphinidin trimer GC-GC-C & & & & 0.0400 \\
\hline Prodelphinin dimer B3 & & & & 0.1800 \\
\hline \multicolumn{5}{|l|}{ Flavanones } \\
\hline 6-Geranylnaringenin & & 0.0011 & 0.0027 & 0.0004 \\
\hline 6-Prenylaringenin & 0.0007 & 0.0200 & 0.0200 & 0.0026 \\
\hline 8-Prenylaringenin & 0.0003 & 0.0044 & 0.0092 & 0.0010 \\
\hline Isoxanthohumol & 0.0100 & 0.2100 & 0.1200 & 0.0400 \\
\hline Naringin & & & & 0.0008 \\
\hline \multicolumn{5}{|l|}{ Flavones } \\
\hline Apigenin & & & & 0.0042 \\
\hline \multicolumn{5}{|l|}{ Flavonols } \\
\hline 3,7-Dimethylquercetin & & & & 0.0003 \\
\hline Myricetin & & & & 0.0007 \\
\hline Quercetin & & & & 0.0067 \\
\hline Quercetin 3-O-arabinoside & & & & 0.0006 \\
\hline Quercetin 3-O-rutinoside & & & & 0.0900 \\
\hline \multicolumn{5}{|l|}{ Isoflavonoids } \\
\hline Biochanin A & & 0.0005 & & 0.0015 \\
\hline Daidzein & & 0.0005 & & \\
\hline Genistein & & 0.0010 & & \\
\hline
\end{tabular}

Data from the Phenol-Explorer database [12].

the quantification of phenolic profiles [12], which, in turn, has led to new studies suggesting that regular polyphenol consumption might provide health benefits for menopausal and postmenopausal women, reducing vasomotor symptoms $[13,14]$ and osteoporosis [15].

Hop (Humulus lupulus $\mathrm{L}$ ) is the ingredient used for beer making and is rich in phenolic compounds. Mass spectrometry analysis show that it contains around $14.4 \%$ of phenolic acids, flavonoids, proanthocyanidins, prenylated chalcones, and catechins [16]. Furthermore, malt provides $70 \%-80 \%$ of the total polyphenolic compounds found in beer [17]. It has been shown through high-performance liquid chromatography and posterior ultrasound separation that fermentation, boiling, and the amount of hop used to manufacture beer significantly influence the final polyphenol concentrations [18].

Menopause is induced by the permanent cessation of menstruation due to the end of ovarian follicular activity. This affects the physiology of women [19] and leads to a diminished production of estradiol which is correlated with the night sweats and hot flushes experienced by many menopausal women [20]. According to the Menopause Epidemiology Study, in which 4402 women were surveyed, these symptoms are one of the main reasons for women to seek medical care and over-the-counter treatments that provide some relief and improve the quality of life [21]. For the present work, we review the current knowledge found through online scientific libraries, PubMed and Scopus, regarding moderate beer consumption, polyphenol intake from beer, and their possible benefits for menopausal women.

\section{Polyphenolic Compounds in Beer}

Beer contains amino acids, carbohydrates, vitamins, minerals, and polyphenols. As mentioned above, beer contains a diversity of polyphenols mainly derived from hops and malt [16, 22]. Moreover, during the beer fermentation process, a resin produced by hops that contains monoacylphlorogucinols is converted into bitter acids such as humulones and isohumulones. These molecules act as bioactive antioxidants and provide additional beneficial effects [23]. 
Tables 1-3 show the polyphenols found in different types of beer. Malt contains many free and total (bound) polyphenolic compounds; according to composition analysis using a liquid chromatography-antioxidant technique before and after fermentation, the concentrations of polyphenolic compounds may be increased by up to threefold after the fermentation process [24]. The main polyphenolic compounds present in beer are sinapic, ferulic, and caffeic acids. Vanillic acids are present in bound and unbound forms while 4hydroxyphenylacetic and p-coumaric acids are present as free forms [17]. The main phenolic acids found in beer are shown in Figure 1.

\section{Polyphenol Metabolites in Plasma}

Analysis of polyphenol concentrations in plasma reveals that after ingestion, beer goes through the gastrointestinal tract. An estimated amount of between $5-10 \%$ of beer is absorbed in the small intestine, with the remaining 90-95\% continuing on to the colon where it is further fermented by the gut microbiota [25], increasing the amount of polyphenols such as 4-hydroxyphenylacetic and vanillic acids absorbed [26-28]. After being absorbed, polyphenols undergo hepatic conjugation reactions with S-adenosyl methionine, sulfates, glucuronates, or a combination of them [29]. After 30 minutes, the plasma levels of nonconjugated hydroxyphenylacetic acid significantly increase. Vanillic, caffeic, and ferulic acid levels raise equally as conjugated and nonconjugated forms, with a slight prevalence of sulfate over glucuronate isoforms [30]. Composition analysis carried out in human urine samples after ingestion of wine, tea, beer, or coffee has shown that polyphenol compounds and metabolites such as resveratrol [31], 4-O-methylgallic acid, isoferulic acid [32], and isoxanthohumol [33] are excreted through renal filtration. Table 4 provides detailed information about the plasma levels of polyphenol metabolites after the ingestion of beer.

\section{Menopause: Physiology, Symptoms, and Current Treatment}

Menopause is defined as the permanent cessation of menstruation as a direct result of the end of ovarian follicular activity [35]. Follicular development is a cyclical process that occurs on average every 28 days during reproductive life. However, with age, these cycles become irregular and then stop completely. This cessation causes abnormal fluctuations of sex hormones, such as the follicle-stimulating hormone (FSH), anti-Müllerian hormone, estrogen, and insulin-like growth factors-I (ILGF-I), which eventually lead to physiological and morphological changes in many organs and systems in women [36].

These physiological changes induce different symptoms and signs which are characteristic of menopausal women, such as irregular bleeding, night sweats, hot flashes, tachycardia, breast pain, lack of energy, dyspareunia, joint soreness, atrophic vaginitis, interrupted sleeping patterns, anxiety, mood swings, dry skin, and loss of libido [37, 38]. Moreover, menopause may also predispose women to a series of risks,
TABle 2: Phenolic acids contained in different types of beer.

\begin{tabular}{|c|c|c|c|c|}
\hline \multirow[b]{2}{*}{ Molecule } & \multicolumn{4}{|c|}{ Mean content $(\mathrm{mg} / 100 \mathrm{ml})$} \\
\hline & $\begin{array}{l}\text { Alcohol- } \\
\text { free }\end{array}$ & Ale & Dark & Regular \\
\hline \multicolumn{5}{|l|}{ Hydroxybenzoic acids } \\
\hline $\begin{array}{l}\text { 2,6-Dihydroxybenzoic } \\
\text { acid }\end{array}$ & & & & 0.0900 \\
\hline 2-Hydroxybenzoic acid & 0.0011 & & & 0.2000 \\
\hline $\begin{array}{l}\text { 3,5-Dihydroxybenzoic } \\
\text { acid }\end{array}$ & & & & 0.0300 \\
\hline 3-Hydroxybenzoic acid & & & & 0.0300 \\
\hline 4-Hydroxybenzoic acid & 0.0073 & 0.1100 & 0.0700 & 0.9600 \\
\hline Gallic acid & & 0.1100 & 0.0300 & 0.0700 \\
\hline Gallic 3-O-gallate & & & & 0.2600 \\
\hline Gentisic acid & & & & 0.0300 \\
\hline Protocatechuic acid & 0.2700 & 0.0600 & 0.0400 & 0.0500 \\
\hline Syringic acid & & 0.1100 & & 0.0200 \\
\hline Vanillic acid & 0.0300 & 0.2900 & 0.1700 & 0.0700 \\
\hline \multicolumn{5}{|l|}{ Hydroxycinnamic acids } \\
\hline 4-Caffeoylquinic acid & & & & 0.0100 \\
\hline 5-Caffeoylquinic acid & & & & 0.0800 \\
\hline Caffeic acid & 0.0100 & 0.0075 & 0.0300 & 0.0300 \\
\hline Ferulic acid & 0.1200 & 0.3300 & 0.0900 & 0.2600 \\
\hline$m$-Coumaric acid & & & & 0.0200 \\
\hline$o$-Coumaric acid & & & & 0.1500 \\
\hline$p$-Coumaric acid & 0.4000 & 0.1200 & 0.0500 & 0.1000 \\
\hline Sinapic acid & 0.0073 & 0.0700 & 0.0300 & 0.0200 \\
\hline \multicolumn{5}{|l|}{ Hydroxyphenylacetic acids } \\
\hline $\begin{array}{l}\text { 4-Hydroxyphenylacetic } \\
\text { acid }\end{array}$ & & & & 0.0300 \\
\hline Homovanillic acid & & & & 0.0500 \\
\hline
\end{tabular}

Data from the Phenol-Explorer database [12].

such as an increased risk of atherosclerosis [39-43], osteopenia, and osteoporosis [44, 45] (Figure 2).

Hot flashes are one of the most frequent symptoms presented by women undergoing menopause. They have a profound impact on the quality of life and increase health costs [46]. Vasomotor symptoms represent one of the main reasons why menopausal women seek medical care and treatments in the hope of relieving their discomfort [47]. Hot flashes are the result of the brain's response to diminished and fluctuating sex hormone concentrations that occur in menopause $[48,49]$. Mechanisms of temperature homeostasis on the hypothalamus and peripheral vasculature are influenced by different hormones such as ovarian hormones, norepinephrine, and serotonin. Kronenberg described the links between vasomotor symptoms and different thermal, hormonal, and autonomic parameters, demonstrating the relevance of hormones in the deregulation of core body temperature that leads to hot flashes in menopause [50].

Current menopausal treatment includes estrogen hormone replacement therapy (HRT); selective estrogen 
TABLE 3: Other phenolic compounds contained in beer.

\begin{tabular}{|c|c|c|c|c|}
\hline \multirow{2}{*}{ Molecule } & \multicolumn{4}{|c|}{ Mean content $(\mathrm{mg} / 100 \mathrm{ml})$} \\
\hline & Alcohol-free & Ale & Dark & Regular \\
\hline 2,3-Dihydroxy-1-guaiacylpropanone & 0.0025 & & & 0.0034 \\
\hline 3-Methylcatechol & & & 0.0029 & 0.0001 \\
\hline 4-Ethylcatechol & & & 0.0010 & 0.0006 \\
\hline 4-Hydroxycoumarin & & & & 0.1100 \\
\hline 4-Methylcatechol & & & 0.0022 & \\
\hline 4-Vinylguaiacol & & 0.0100 & 0.0300 & 0.1500 \\
\hline 4-Vinylphenol & & & 0.0300 & 0.0045 \\
\hline Catechol & & & 0.0100 & 0.0011 \\
\hline Esculin & & & & 0.0200 \\
\hline Pyrogallol & & & 0.0300 & 0.0047 \\
\hline Tyrosol & 0.2700 & & & 0.3200 \\
\hline Umbelliferone & & & & 0.0017 \\
\hline Vanillin & 0.0048 & & & 0.0200 \\
\hline
\end{tabular}

Data from the Phenol-Explorer database [12].

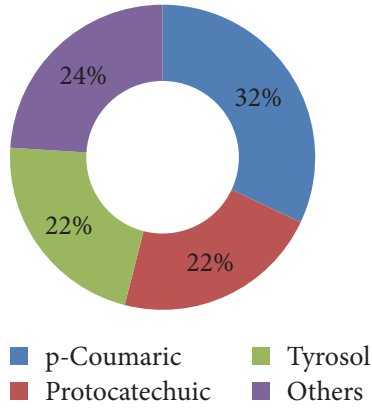

(a)

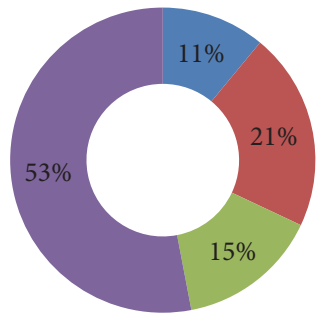

- Ferulic Vanillic
Isoxanthohumol - Others

(c)

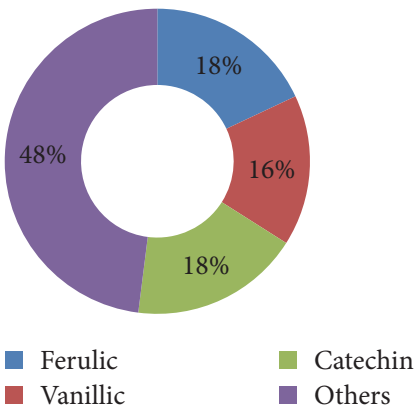

(b)

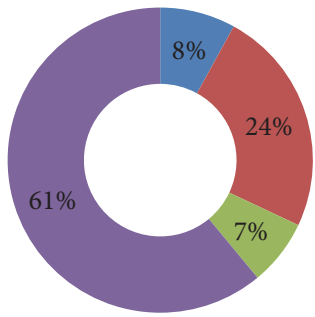

$\begin{array}{ll}\text { Tyrosol } & \text { Ferulic } \\ \text { 4-Hydroxybenzoic } & \text { Others }\end{array}$

(d)

Figure 1: Main polyphenol content in different types of beer presented in percentages: (a) alcohol-free beer; (b) ale beer; (c) dark beer; (d) regular beer.

receptor modulators, such as tamoxifen and raloxifene [51]; and other medications such as selective serotonin reuptake inhibitors that alleviate vasomotor symptoms [52]. However, in different studies carried out in human patients, it has been suggested that HRT has no benefit in preventing cardiovascular disease and may even lead to an increased risk of arterial and venous thrombotic events [53], ovarian cancer [54], nonalcoholic steatohepatitis [55], and other diseases. These reports have encouraged scientists to find alternative and safer treatment options for menopausal symptoms.

\section{Moderate Beer Intake and Health}

Although it is well known that ethanol is a carcinogenic substance for humans [56], several studies have shown that regular and moderate intake of fermented beverages, such as wine and beer, may be associated with different positive 
TABLE 4: Mean plasmatic levels of polyphenolic metabolites after beer intake.

\begin{tabular}{|c|c|c|c|c|}
\hline Polyphenolic metabolite & Dose per day & Mean concentration (plasma) & T-Max (h) & Ref. \\
\hline Ferulic acid & $500 \mathrm{ml}$ & $0.11 \mu \mathrm{mol} / \mathrm{l}$ & 0.5 & {$[34]$} \\
\hline 4-Hydroxyphenylacetic acid & $500 \mathrm{ml}$ & $1.4 \mu \mathrm{mol} / \mathrm{l}$ & 0.5 & {$[30]$} \\
\hline Vanillic acid & $500 \mathrm{ml}$ & $0.11 \mu \mathrm{mol} / 1$ & 0.5 & [30] \\
\hline$p$-Coumaric acid & $500 \mathrm{ml}$ & $0.05-0.07 \mu \mathrm{mol} / 1$ & 0.5 & {$[30]$} \\
\hline Caffeic acid & $500 \mathrm{ml}$ & $0.05-0.07 \mu \mathrm{mol} / 1$ & 0.5 & [30] \\
\hline
\end{tabular}

T-Max: time when maximal concentration is achieved.

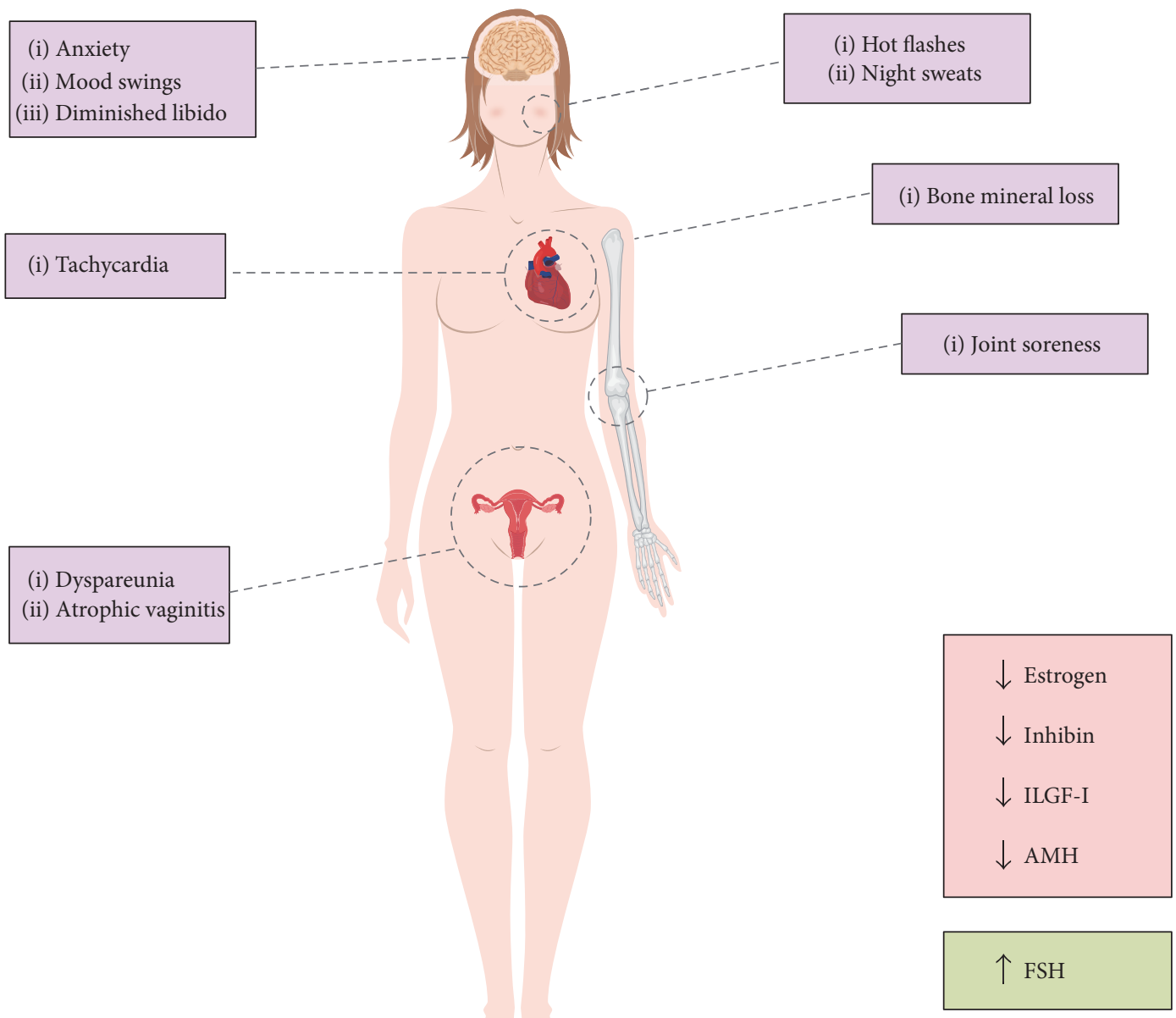

FIGURE 2: Sexual hormone status and common clinical manifestations in menopause. Insulin-like growth factor I (ILGF-I); anti-Müllerian hormone (AMH); follicle-stimulating hormone (FSH).

health effects, such as the reduction in the risk of cardiovascular disease as evidenced by the J-shaped relation found in wine [57] and beer [58] intake on cardiovascular risk, the reduction in atheroma plaque formation [59], prevention on different cancer types $[23,60,61]$, and the reduction in bone mineral loss that leads to osteoporosis and osteopenia $[15,62]$. The lack of evidence attributing the same effects to spirit intake suggests that polyphenolic compounds might play an important role in the beneficial effects of moderate alcoholic beverage intake on several health outcomes [63-66].

\section{Beer and Menopause}

Several intervention studies have evaluated the effects of beer and menopause. An 8-week, randomized, double-blind, cross-over trial showed that consuming 8-prenylnaringenin (8-PN), a characteristic polyphenol from hops and beer, resulted in a significant reduction in menopause symptoms [14] and discomforts [67]. Vasomotor symptoms are believed to be caused by a slight increase in body temperature in conjunction with a smaller thermo-neutral zone [68]. These processes are controlled by a region of the anterior 


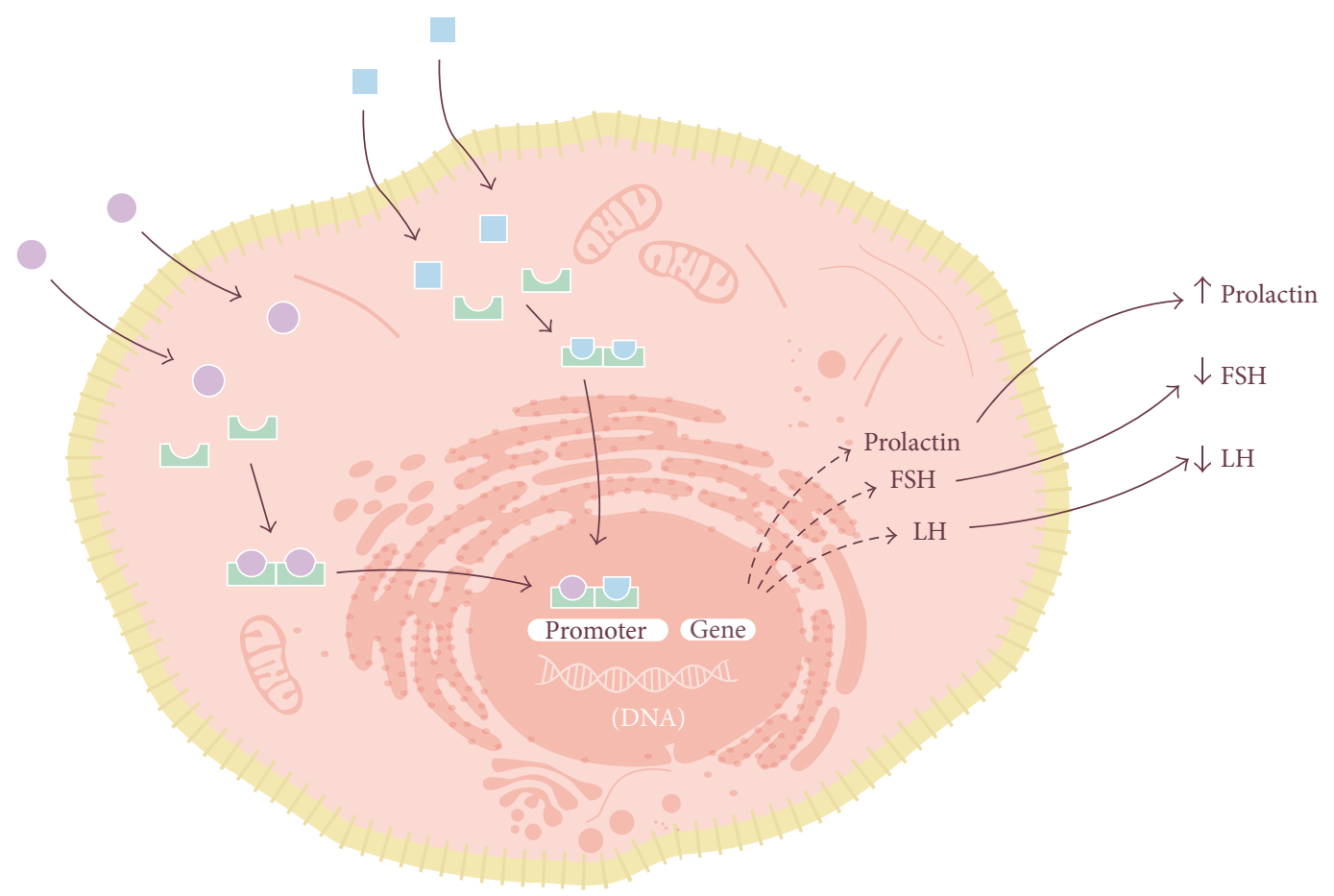

$17-\beta$-Estrogen

8-Prenylnaringenin

6-Prenylnaringenin

Isoxanthohumol

Estrogen receptor

FIGURE 3: Mechanism of phytoestrogens. Like estrogen, phytoestrogen molecules travel through plasma and diffuse into the target cells, where they bind to cytoplasmatic estrogen receptors (ER). The new molecule-ER complex then dimerizes and is translocated into the nucleus, where it binds to specific promoters that decrease the expression of genes translating hormones such as follicle-stimulating hormone (FSH) and luteinizing hormone $(\mathrm{LH})$ and promote the translation of prolactin. The use of estrogen receptors by 17-b-estrogen and molecules such as 8-prenylaringenin, 6-prenylaringenin, and isoxanthohumol explains why these molecules can be used to decrease the intensity of many classical symptoms of menopause.

hypothalamus called the thermoregulatory nucleus. This area responds to sex hormones as shown by experimental models with ovariectomized rats. These rats presented significant differences in body temperature compared to a unovariectomized control group, and the differences reversed when the rats were treated with estrogens or clonidine, an alphaadrenoceptor used for vasomotor symptom treatment, suggesting that temperature irregularities in menopause may be due to changes in the sex hormone regulatory system [69]. In the same animal model, low doses of approximately $400 \mu \mathrm{g} / \mathrm{kg} /$ day of 8 -prenylnaringenin were also able to alleviate menopausal vasomotor symptoms [70].

The effect of 8-prenylnaringenin may be explained by its strong affinity for both alpha and beta estrogen receptors (ER). The binding of 8-PN and the consequent activation of ERs lead to the stimulation of alkaline phosphatase activity and upregulate the activity of progesterone receptors and presenelin-2 [14], both of which are estrogen-stimulated genes (Figure 3). In addition, low doses of 8-prenylnaringenin increase the libido of menopausal women [71].

The absorption of hop phenolic acid and the pharmacokinetics and possible health benefits of hops have been studied in women [72]; however, at present, no clinical trial has assessed the effects of moderate beer consumption on menopausal women.

\section{Summary}

Menopause is a physiological condition that causes significant discomfort in many women around the world with the presentation of a myriad of symptoms related to an imbalance in sex hormone levels. Hot flashes and night sweats are two of the most common clinical findings in menopausal women that lead them to seek medical care. Since traditional hormone replacement therapies increase health risks, alternative, safer treatment options are needed. Hop and beer polyphenols seem to be an alternative to alleviate the menopausal symptoms presented by women.

There is evidence that regular and moderate intake of the polyphenols commonly found in hop and beer may help to relieve many common symptoms presented by women undergoing menopause. Said benefits can also be obtained by menopausal women from regular alcohol-free beer consumption, since ingredients used and most processes are 
shared between alcohol-free and regular beer. Alcohol-free beer could provide women with all the same possible benefits, without the risk of gastrointestinal pathologies and cancer that frequent alcohol consumption represents to health. Nonetheless, randomized intervention clinical trials are needed to confirm their efficacy.

\section{Disclosure}

No foundation or institution was involved in the writing of the manuscript or the decision to submit the manuscript for publication.

\section{Conflicts of Interest}

Anna Tresserra-Rimbau, Rosa M. Lamuela-Raventós, and Ramon Estruch have received funding from The European Foundation for Alcohol Research (ERAB). Rosa M. Lamuela-Raventós and Ramon Estruch report serving on the board of and receiving lecture fees from Research Foundation on Wine and Nutrition (FIVIN) and Cerveceros de España. Rosa M. Lamuela-Raventós has received lecture fees and travel support from PepsiCo, and Ramon Estruch reports serving on the boards of the Mediterranean Diet Foundation, receiving lecture fees from Sanofi-Aventis, and receiving grant support through his institution from Novartis.

\section{Acknowledgments}

This work was supported by the European Foundation for Alcohol Research (ERAB) (EA 1324, EA 1514, EA 1515, and EA 1517), the CICYT (AGL2016-79113-R), and the Instituto de Salud Carlos III (ISCIII) (CIBEROBN) from the Ministerio de Economía, Industria y Competitividad (MEIC) (AEI/FEDER, UE) and Generalitat de Catalunya (GC) (2014 SGR 773).

\section{References}

[1] World Health Organization, Alcohol in the European Union. Consumption, Harm and Policy Approaches, World Health Organization, Regional office for Europe, Copenhaguen, Denmark, 2012.

[2] M. Adjemian and R. Volpe, Alcohol consumption and food-athome dietary quality in the United States, Journal of Wine Economics. 2012 Annual Meeting, August 12-14, Agricultural and Applied Economics Association, Seattle, Washington, WA, USA, 2012.

[3] W. Jiajing, L. Li, B. Terry, Y. Linjie, L. Yuanqing, and X. Fulai, "Revealing a 5,000-y-old beer recipe in China," Proceedings of the National Academy of Sciences of the United States of America, vol. 113, no. 23, pp. 6444-6448, 2016.

[4] R. W. Unger, Beer in the Middle Ages and the Renaissance Philadelphia, University of Pennsylvania Press, Philadelphia, PA, USA, 2007.

[5] L. C. Nogueira, R. F. do Rio, P. C. Lollo, and I. M. Ferreira, "Moderate alcoholic beer consumption: the effects on the lipid profile and insulin sensitivity of adult men," Journal of Food Science, vol. 82, no. 7, pp. 1720-1725, 2017.
[6] C. Matsumoto, M. D. Miedema, P. Ofman, J. M. Gaziano, and H. D. Sesso, "An expanding knowledge of the mechanisms and effects of alcohol consumption on cardiovascular disease," Journal of Cardiopulmonary Rehabilitation and Prevention, vol. 34, no. 3, pp. 159-171, 2014.

[7] S. Arranz, G. Chiva-Blanch, P. Valderas-Martínez, A. MedinaRemón, R. M. Lamuela-Raventós, and R. Estruch, "Wine, beer, alcohol and polyphenols on cardiovascular disease," Nutrients, vol. 4, no. 7, pp. 759-781, 2012.

[8] A. Hernandez-Hernandez, A. Gea, M. Ruiz-Canela et al., "Mediterranean alcohol-drinking pattern and the incidence of cardiovascular disease and cardiovascular mortality: the SUN project," Nutrients, vol. 7, no. 11, pp. 9116-9126, 2015.

[9] G. Chiva-Blanch, E. Magraner, X. Condines et al., "Effects of alcohol and polyphenols from beer on atherosclerotic biomarkers in high cardiovascular risk men: a randomized feeding trial," Nutrition, Metabolism, and Cardiovascular Diseases, vol. 25, no. 1, pp. 36-45, 2015.

[10] A. Di Castelnuovo, S. Costanzo, R. di Giuseppe, G. de Gaetano, and L. Iacoviello, "Alcohol consumption and cardiovascular risk: mechanisms of action and epidemiologic perspectives," Future Cardiology, vol. 5, no. 5, pp. 467-477, 2009.

[11] T. Brügger-Andersen, V. Pönitz, S. Snapinn, and K. Dickstein, "Moderate alcohol consumption is associated with reduced long-term cardiovascular risk in patients following a complicated acute myocardial infarction," International Journal of Cardiology, vol. 133, no. 2, pp. 229-232, 2009.

[12] J. A. Rothwell, J. Pérez-Jiménez, V. Neveu et al., "Phenolexplorer 3.0: a major update of the phenol-explorer database to incorporate data on the effects of food processing on polyphenol content," Database: The Journal of Biological Databases and Curation, vol. 2013, 2013.

[13] K. Annekathrin, Z. Oliver, and K. Georg, "Hop extracts and hop substances in treatment of menopausal complaints," Planta Medica, vol. 79, no. 7, pp. 576-579, 2013.

[14] A. Fatemeh, M. Hamid, and R. Nasibeh, "Hops for menopausal vasomotor symptoms: mechanisms of action," Journal of Menopausal Medicine, vol. 22, no. 2, pp. 62-64, 2016.

[15] J. Pedrera-Zamorano, J. Lavado-Garcia, R. Roncero-Martin, J. Calderon-Garcia, T. Rodriguez-Dominguez, and M. CanalMacias, "Effect of beer drinking on ultrasound bone mass in women," Nutrition, vol. 25, no. 10, pp. 1057-1063, 2009.

[16] A. W. Taylor, E. Barofsky, J. A. Kennedy, and M. L. Deinzer, "Hop (Humulus lupulus L.) proanthocyanidins characterized by mass spectrometry, acid catalysis, and gel permeation chromatography," Journal of Agricultural and Food Chemistry, vol. 51, no. 14, pp. 4101-4010, 2013.

[17] P. Quifer-Rada, A. Vallverdú-Queralt, M. Martínez-Huélamo et al., "A comprehensive characterisation of beer polyphenols by high resolution mass spectrometry (LC-ESI-LTQOrbitrap-MS)," Food Chemistry, vol. 169, pp. 336-343, 2015.

[18] D. Intelmann, G. Haseleu, and T. Hofmann, "LC-MS/MS quantitation of hop-derived bitter compounds in beer using the ECHO technique," Journal of Agricultural and Food Chemistry, vol. 57, no. 4, pp. 1172-1182, 2009.

[19] J. E. Hall, "Neuroendocrine physiology of the early and late menopause," Endocrinology and Metabolism Clinics of North America, vol. 33, no. 4, pp. 637-659, 2004.

[20] A. Ziv-Gal and J. A. Flaws, "Factors that may influence the experience of hot flushes," Journal of Women's Health, vol. 19, no. 10, pp. 1905-1914, 2010. 
[21] F. Kronenberg, "Menopausal hot flashes: a review of physiology and biosociocultural perspective on methods of assessment," The Journal of Nutrition, vol. 140, no. 7, pp. 1380S-1385S, 2010.

[22] D. De Keukeleire, L. De Cooman, H. Rong, A. Heyerick, J. Kalita, and S. R. Milligan, "Functional properties of hop polyphenols," Basic Life Sciences, vol. 66, pp. 739-760, 1999.

[23] C. Gerhauser, "Beer constituents as potential cancer chemopreventive agents," European Journal of Cancer, vol. 41, no. 13, pp. 1941-1954, 2005.

[24] C. Leitao, E. Marchioni, M. Bergaentzlé et al., "Effects of processing steps on the phenolic content and antioxidant activity of beer," Journal of Agricoultural and Food Chemistry, vol. 59, no. 4, pp. 1249-1255, 2011.

[25] M. N. Clifford, "Diet-derived phenols in plasma and tissues and their implications for health," Planta Medica, vol. 70, no. 12, pp. 1103-1114, 2004.

[26] C. Cueva, I. Gil-Sánchez, B. Ayuda-Durán et al., “An integrated view of the effects of wine polyphenols and their relevant metabolites on gut and host health," Molecules, vol. 22, no. 1, 2017.

[27] M. Monagas, M. Urpi-Sarda, F. Sánchez-Patán et al., "Insights into the metabolism and microbial biotransformation of dietary flavan-3-ols and the bioactivity of their metabolites," Food \& Function, vol. 1, no. 3, pp. 233-253, 2010.

[28] T. Requena, M. Monagas, M. Pozo-Bayón et al., "Perspectives of the potential implications of wine polyphenols on human oral and gut microbiota," Trends in Food Science \& Technology, vol. 21, no. 7, pp. 332-344, 2010.

[29] A. Scalbert and G. Williamson, "Dietary intake and bioavailability of polyphenols," Journal of Nutrition, vol. 130, no. 8S, pp. 2073S-2085S, 2000.

[30] M. Nardini, F. Natella, C. Scaccini, and A. Chiselli, "Phenolic acids from beer are absorbed and extensively metabolized in humans," The Journal of Nutritional Biochemistry, vol. 17, no. 1, pp. 14-22, 2006.

[31] R. Zamora-Ros, M. Urpi-Sarda, R. M. Lamuela-Raventós et al., "Diagnostic performance of urinary resveratrol metabolites as a biomarker of moderate wine consumption," Clinical Chemistry, vol. 52, no. 7, pp. 1373-1380, 2006.

[32] J. M. Hodgson, S. Y. Chan, I. B. Puddey et al., "Phenolic acid metabolites as biomarkers for tea- and coffee-derived polyphenol exposure in human subjects," The British Journal of Nutrition, vol. 91, no. 2, pp. 301-306, 2004.

[33] P. Quifer-Rada, M. Martínez-Huelamo, G. Chiva-Blanch, O. Jauregui, R. Estruch, and R. M. Lamuela-Raventós, "Urinary isoxanthohumol is a specific and accurate biomarker of beer consumption," The Journal of Nutrition, vol. 144, no. 4, pp. 484-488, 2014.

[34] R. A. Canccetta, K. D. Croft, L. J. Beilin, and I. B. Puddey, "Ingestion of red wine significantly increases plasma phenolic acid concentrations but does not acutely affect ex vivo lipoprotein oxidizability," American Journal of Clinical Nutrition, vol. 71, no. 1, pp. 67-74, 2000.

[35] J. S. Berek, Berek and Novak's Gynecology, Lippincott Williams and Wilkins, Philadelphia, PA, USA, 15th edition, 2012.

[36] M. R. Sowers, A. D. Eyvazzadeh, D. McConnell et al., "Anti-Mullerian hormone and inhibin B in the definition of ovarian aging and the menopause transition," Journal of Clinical Endocrinology and Metabolism, vol. 93, no. 9, pp. 3478-3483, 2008.
[37] P. Llaneza, M. P. García-Portilla, D. Llaneza-Suárez, B. Armott, and F. R. Pérez-López, "Depressive disorders and the menopause transition," Maturitas, vol. 71, no. 2, pp. 120130, 2012.

[38] B. Hoffman, J. Schorge, J. Schaffer, L. Halvorson, K. Bradshaw, and F. Cunningham, Williams Gynecology, McGraw-Hill Medical, New York, NY, USA, 2nd edition, 2012.

[39] H. Souza and G. Tezini, "Autonomic cardiovascular damage during post-menopause: the role of physical training," Aging and Disease, vol. 4, no. 6, pp. 320-328, 2013.

[40] V. Malinauskiene and A. Tamosiunas, "Menopause and myocardial infarction risk among employed women in relation to work and family psychosocial factors in Lithuania," Maturitas, vol. 66, no. 1, pp. 94-98, 2010.

[41] I. A. Ebong, K. E. Watson, D. C. Goff et al., "Age at menopause and incident heart failure: the multi-ethnic study of atherosclerosis," Menopause, vol. 21, no. 6, pp. 585-591, 2014.

[42] E. Barrett-Connor, "Menopause, atherosclerosis, and coronary artery disease," Current Opinion in Pharmacology, vol. 13, no. 2, pp. 186-191, 2013.

[43] M. Wellons, P. Ouyang, P. J. Schreiner, D. M. Herrington, and D. Vaidya, "Early menopause predicts future coronary heart disease and stroke: the multi-ethnic study of atherosclerosis," Menopause, vol. 19, no. 10, pp. 1081-1087, 2012.

[44] D. McLemon, J. Powell, R. Jugdaohsingh, and H. Macdonald, "Do lifestyle choices explain the effect of alcohol on bone mineral density in women around menopause," The American Journal of Clinical Nutrition, vol. 95, no. 5, pp. 1261-1269, 2012.

[45] L. Baig, F. A. Mansuri, and S. A. Karim, "Association of menopause with osteopenia and osteoporosis: results from population based study done in Karachi," Journal of the College of Physicians and Surgeons-Pakistan, vol. 19, no. 4, pp. 240244, 2009.

[46] W. H. Utian, "Psychosocial and socioeconomic burden of vasomotor symptoms in menopause: a comprehensive review," Health and Quality of Life Outcomes, vol. 3, no. 1, p. 47, 2005.

[47] R. E. Williams, L. Kalilani, D. B. DiBenedetti, X. Zhou, S. E. Fehnel, and R. V. Clark, "Healthcare seeking and treatment for menopausal symptoms in the United States," Maturitas, vol. 58, no. 4, pp. 348-358, 2007.

[48] R. R. Friedman, "Pathophysiology and treatment of menopausal hot flashes," Seminars in Reproductive Medicine Journal, vol. 23, no. 2, pp. 117-125, 2005.

[49] D. C. Deecher, "Physiology of thermoregulatory dysfunction and current approaches to the treatment of vasomotor symptoms," Expert Opinion on Investigational Drugs, vol. 14, no. 4, pp. 434-448, 2005.

[50] F. Kronenberg, "Hot flashes: epidemiology and physiology," Annals of the New York Academy of Sciences, vol. 592, pp. 52-86, 1990.

[51] S. R. Davis, I. Dinatale, L. Rivera-Woll, and S. Davison, "Postmenopausal hormone therapy: from monkey glands to transdermal patches," Journal of Endocrinology, vol. 185, no. 2, pp. 207-222, 2005.

[52] M. S. Krause and S. T. Nakajima, "Hormonal and nonhormonal treatment of vasomotor symptoms," Obstetrics and Gynecology Clinics of North America, vol. 42, no. 1, pp. 163179, 2015. 
[53] H. M. Boardman, L. Hartley, A. Eisinga et al., "Hormone therapy for preventing cardiovascular disease in post-menopausal women," The Cochrane Database of Systematic Reviews, vol. 10, no. 3, 2015.

[54] C. La Vecchia, "Ovarian cancer: epidemiology and risk factors," European Journal of Cancer Prevention, vol. 26, no. 1, pp. 55-62, 2017.

[55] J. D. Yang, M. F. Abdelmalek, C. D. Guy et al., "Patient sex, reproductive status, and synthetic hormone use associate with histologic severity of nonalcoholic steatohepatitis," Clinical Gastroenterology and Hepatology, vol. 15, no. 1, pp. 127-131, 2017.

[56] World Health Organization and International Agency for Research on Cancer. IARC, "Monographs on the evaluation of carcinogenic risks to humans: alcohol consumption and ethyl carbamate," in Monographs on the Evaluation of Carcinogenic Risks to Humans, World Health Organization, International Agency for Research on Cancer, Lyon, France, 2010, Report No.: 96.

[57] R. Estruch, M. Urpi-Sarda, G. Chiva, E. S. Romero, M. I. Covas, and J. Salas-Salvadó, Cerveza, Dieta Mediterránea y Enfermedad Cardiovascular. Dossier de Prensa, Madrid, Spain, Centro de Información Cerveza y Salud, Cerveza y Salud, 2011.

[58] S. Costanzo, A. Di Castelnuovo, M. B. Donati, L. Iacoviello, and W. de Gaetano, "Wine, beer or spirit drinking in relation to fatal and non-fatal cardiovascular events: a meta-analysis," European Journal of Epidemiology, vol. 26, no. 11, pp. 833850, 2011.

[59] L. Brown, P. Kroon, D. Das et al., "The biological responses to resveratrol and other polyphenols from alcoholic beverages," Alcoholism, Clinical and Experimental Research, vol. 33, no. 9, pp. 1513-1526, 2009.

[60] M. N. Gronbaek, T. I. Sorensen, D. Johansen et al., "Beer, wine, spirits and mortality," Läkartidningen, vol. 98, no. 21, pp. 2585-2588, 2001

[61] S. Renaud, D. Lanzmann-Petithory, R. Gueguen, and P. Conard, "Alcohol and mortality from all causes," Biological Research, vol. 37, pp. 183-187, 2004.

[62] K. L. Tucker, R. Jugdaohsing, J. J. Powell et al., "Effects of beer, wine, and liquor intakes on bone mineral density in older men and women," American Journal of Clinical Nutrition, vol. 89, no. 4, pp. 1188-1196, 2009.

[63] P. Gresele, C. Cerletti, G. Guglielmini, P. Pignatelli, G. de Gaetano, and F. Violi, "Effects of resveratrol and other wine polyphenols on vascular function: an update," Journal of Nutritional Biochemistry, vol. 22, no. 3, pp. 202-211, 2011.

[64] N. Martinez, M. Urpi-Sarda, M. A. Martinez-Gonzalez, C. Andres-Lacueva, and M. T. Mitjavila, "Dealcoholised beers reduce atherosclerosis and expression of adhesion molecules in apoE-deficient mice," British Journal of Nutrition, vol. 105, no. 5, pp. 721-730, 2011.

[65] A. Piazzon, M. Forte, and M. Nardini, "Characterization of phenolics content and antioxidant activity of different beer types," Journal of Agricultural and Food Chemistry, vol. 58, no. 19, pp. 10677-10683, 2010.

[66] R. Estruch, E. Sacanella, E. Badia et al., "Different effects of red wine and gin consumption on inflammatory biomarkers of atherosclerosis: a prospective randomized crossover trial. Effects of wine on inflammatory markers," Atherosclerosis, vol. 175, no. 1, pp. 117-123, 2004.
[67] R. Erkkola, S. Vervarcke, S. Vansteelandt, P. Rompotti, D. DeKeukeleire, and A. Heyerick, "A randomized, double-blind, placebo-controlled, cross-over pilot study on the use of a standardized hop extract to alleviate menopausal discomforts," Phytomedicine, vol. 17, no. 6, pp. 389-396, 2010.

[68] R. R. Friedman, "Hot flashes: behavioral treatments, mechanisms, and relation," American Journal of Medicine, vol. 118, no. 12Bf, pp. 124-130, 2005.

[69] H. H. Berendsen, A. H. Weekers, and H. J. Kloosterboer, "Effect of tibolone and raloxifene on the tail temperature of oestrogen-deficient rats," European Journal of Pharmacology, vol. 419, no. 1, pp. 47-54, 2001.

[70] J. Bowe, X. F. Li, J. Kinsey-Jones et al., "The hop phytoestrogen, 8-prenylnaringenin, reverses the ovariectomy-induced rise in skin temperature in an animal model of menopausal hot flushes," Journal of Endocrinology, vol. 191, no. 2, pp. 399405, 2006.

[71] A. Keiler, O. Zierau, and G. Kretzschmar, "Hop extracts and hop substances in treatment of menopausal complaints," Planta Medica, vol. 79, no. 7, pp. 576-579, 2013.

[72] R. B. Van Breemen, Y. Yang, S. Banuvar et al., "Pharmacokinetics of prenylated hop phenols in women following oral administration of a standardized extract of hops," Molecular Nutrition \& Food Research, vol. 58, no. 10, pp. 1962-1969, 2014. 


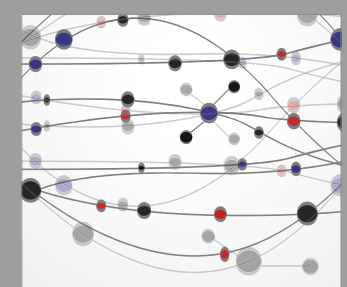

The Scientific World Journal
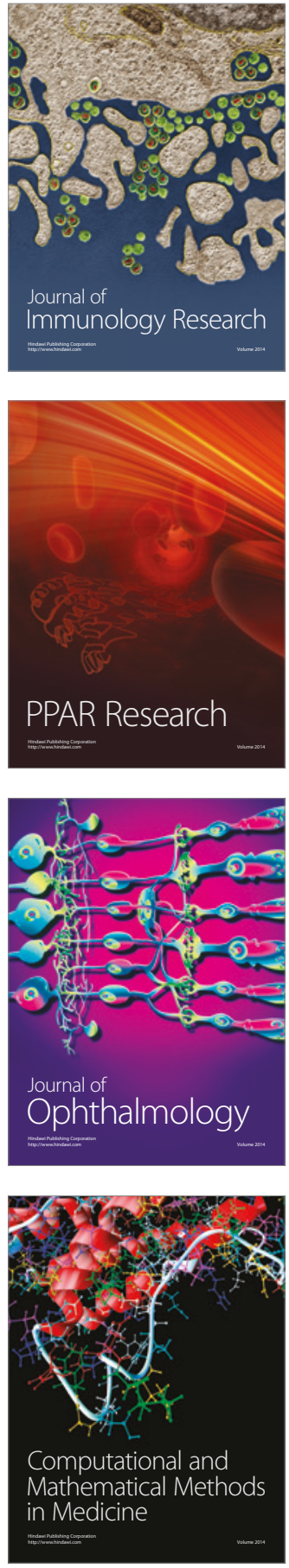

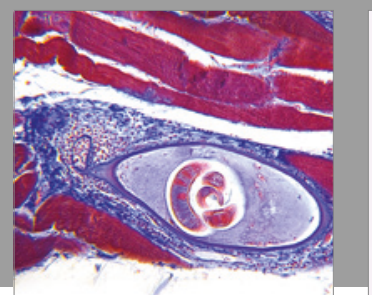

Gastroenterology Research and Practice
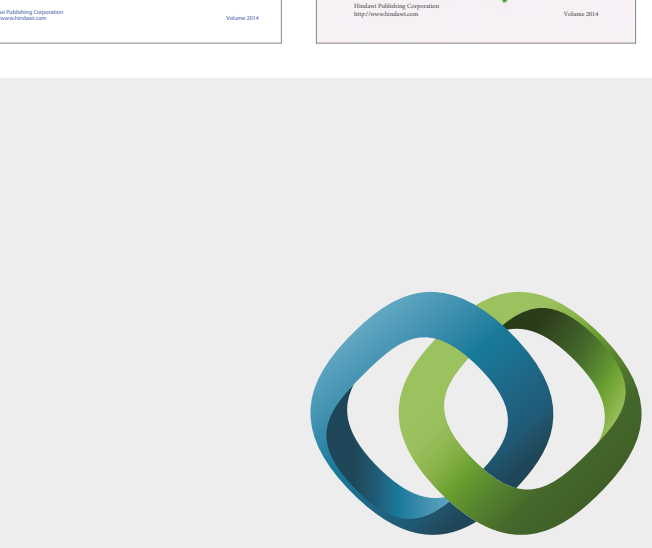

\section{Hindawi}

Submit your manuscripts at

https://www.hindawi.com
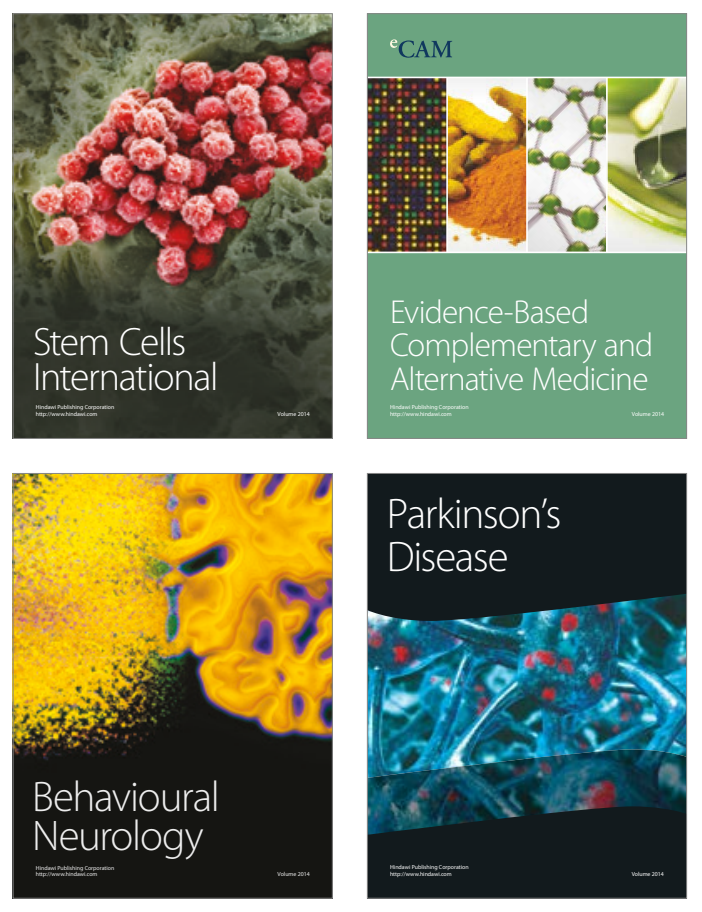
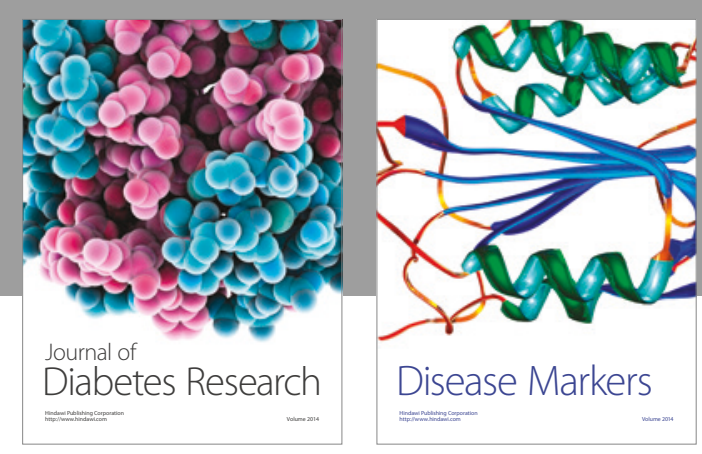

Disease Markers
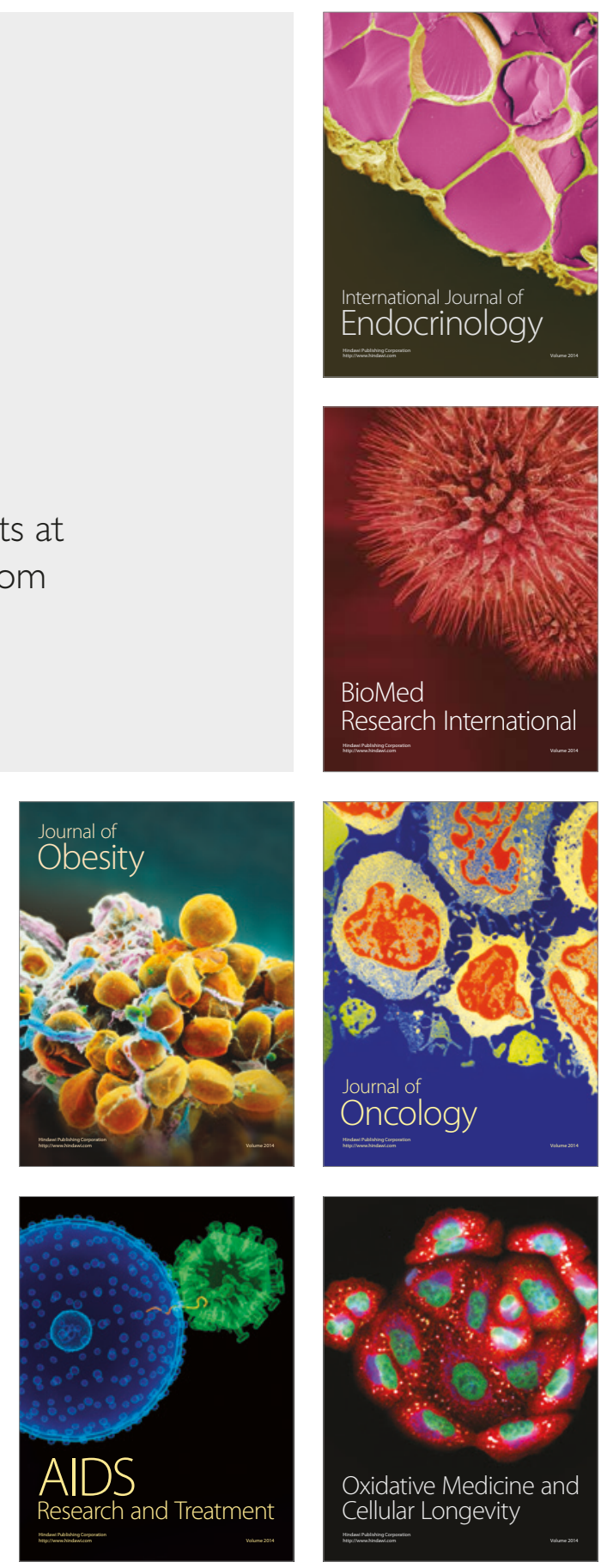